\title{
Potencialidades da compra institucional na promoção de sistemas agroalimentares locais e sustentáveis: o caso de um restaurante universitário
}

\author{
Suellen Secchi Martinelli, ${ }^{1}$ Panmela Soares ${ }^{2}$, Rafaela Karen Fabri ${ }^{3}$, Graziella Regina Alba \\ Campanella $^{4}$, Oscar José Rover ${ }^{5}$ Suzi Barletto Cavalli ${ }^{6}$
}

O objetivo foi analisar a potencialidade da compra institucional de alimentos para a promoção de sistemas sustentáveis e localizados de produção. Analisou-se a demanda de alimentos de um Restaurante Universitário do Sul do Brasil a partir da quantidade e da variedade dos alimentos presentes em listas de compras. Os alimentos foram categorizados em grupos e de acordo com a forma de produção e grau de processamento. Os dados evidenciam grande potencial de compra do restaurante, correspondendo a aproximadamente 77 toneladas mensais. Verificou-se uma grande demanda por alimentos com algum grau de processamento, como higienização e cortes em $100 \%$ das hortaliças e $22 \%$ das frutas, o que pode limitar o acesso dos agricultores familiares num primeiro momento, mas representar um ganho potencial àqueles que se organizarem. A aquisição de alimentos orgânicos ainda é restrita (5\% do total), porém evidencia interesse e esforço crescente para adquiri-los. Os resultados demonstram o potencial do restaurante para a promoção de sistemas sustentáveis e localizados de produção, principalmente diante do interesse da compra de alimentos orgânicos e da grande demanda de alimentos, com e sem processamento. A modalidade "Compra Institucional" do Programa de Aquisição de Alimentos pode auxiliar nesse processo, beneficiando agricultores e consumidores do restaurante.

Palavras-chave: agricultura familiar, compra local, Unidade de Alimentação e Nutrição, Programa de Aquisição de Alimentos.

\footnotetext{
${ }^{1}$ Universidade Federal de Santa Catarina, Programa de Pós-Graduação em Nutrição. Bolsista de Doutorado da FAPESC - Fundação de Amparo à Pesquisa e Inovação do Estado de Santa Catarina. Correspondência: Centro de Ciências da Saúde, Campus Reitor João David Ferreira Lima, Trindade, CEP: 88040-900, Florianópolis, SC, Brasil. E-mail: suellen.smartinelli@gmail.com

2 Universidad de Alicante, Facultad de Ciencias de La Salud, Departamento de Enfermeria Comunitária, Medicina Preventiva y Salud Pública e História de la Ciencia. Bolsista de Doutorado da Fundação CAPES, Ministério da Educação Brasil, Brasília - DF.

${ }^{3}$ Universidade Federal de Santa Catarina, Centro de Ciências da Saúde, Departamento de Nutrição.

${ }^{4}$ Universidade Federal de Santa Catarina, Restaurante Universitário da UFSC.

${ }^{5}$ Universidade Federal de Santa Catarina, Centro de Ciências Agrárias, Departamento de Zootecnia e Desenvolvimento Rural, Programa de Pós-Graduação em Agroecossistemas.

${ }^{6}$ Universidade Federal de Santa Catarina, Centro de Ciências da Saúde, Departamento de Nutrição, Programa de Pós-Graduação em Nutrição.
} 


\section{Potentialities of institutional purchasing in local and sustainable agrifood systems promotion: the case of a university restaurant}

The objective was to analyze the potentiality of institutional food purchasing for the promotion of sustainable and local production systems. We analyzed the demand for food of a University Restaurant in the south of Brazil from the amount and variety of food in shopping lists. The food was categorized into groups and according to the form of production and degree of processing. The data show great purchase potential from the restaurant, corresponding to about 77 tons per month. There was a great demand for food with some degree of processing, such as hygienization and cuts in $100 \%$ of vegetables and $22 \%$ of fruit, which can limit the access of family farmers at first, but could represent a potential gain to those who organize themselves. The purchase of organic food is still restricted (5\% of the total), but it highlights the interest and growing effort to acquire them. The results show the potential of the restaurant for the promotion of sustainable and local production systems, mainly on the interest of buying organic food and the great demand of food, with and without processing. The modality "Institutional Purchase" of the Food Acquisition Program can assist in this process, benefiting farmers and restaurant consumers.

Key-words: family farming, local purchasing, food and nutrition units, Food Acquisition Program.

\section{INTRODUÇÃO}

Frente a sua intrínseca relação com a garantia da Segurança Alimentar e Nutricional (SAN), a agricultura familiar vem ganhando reconhecimento e visibilidade nos últimos anos. Organismos internacionais, como a Organização das Nações Unidas para Alimentação e Agricultura (FAO), reconheceram essa relação diante da declaração do ano internacional da agricultura familiar em 2014, afirmando a centralidade deste seguimento produtivo nas políticas agrícolas e de SAN [1] e para o desenvolvimento de territórios locais.

A magnitude da produção de base familiar para a garantia da SAN é evidenciada pela sua representatividade na produção de alimentos básicos, destinados ao consumo nacional e fundamentais para uma dieta saudável. Na América Latina e no Caribe, a agricultura familiar é responsável pela produção da maioria desses alimentos, como por exemplo, no caso brasileiro, onde $67 \%$ do feijão, $84 \%$ da mandioca, $52 \%$ do leite e $49 \%$ do milho são provenientes desse seguimento produtivo [2, 3]. Além disso, vem sendo apontada como estratégica para o fomento da economia local, proteção da agrobiodiversidade e dos alimentos tradicionais [4].
Considerando o exposto, a FAO, o Programa Mundial de Alimentos (PMA) e a Organização Mundial da Saúde (OMS) vêm referenciando a necessidade de desenvolvimento de políticas e programas voltados para o fortalecimento da agricultura familiar e a aproximação entre produção e consumo de alimentos. Neste contexto, evidencia-se no Brasil o interesse em fomentar os sistemas agrícolas produtivos localizados a partir do desenvolvimento de políticas de compras diretas de agricultores familiares. Essas políticas iniciaram no país no ano de 2003, com a criação do Programa de Aquisição de Alimentos (PAA). A experiência proporcionada pelo PAA impulsionou $\mathrm{O}$ abastecimento do Programa Nacional de Alimentação Escolar (PNAE) com alimentos da agricultura familiar, qualificado com a promulgação da Lei no 11.947 de 2009 [5.

Com o intuito de promover a aquisição de alimentos da agricultura familiar pelos demais equipamentos públicos, como hospitais, penitenciárias, restaurantes populares e universitários, recentemente $\mathrm{O}$ PAA inaugurou a modalidade "Compra Institucional" (Art. 17 do Decreto no 7.775, de 4 julho de 2012, regulamentado pela Resolução no 50, de 26 de setembro de 2012, da Secretaria Nacional de Segurança Alimentar e Nutricional) [6, 7]. Tal modalidade permite que instituições públicas com demandas regulares de gêneros alimentícios comprem os produtos diretamente de agricultores familiares sem a 
necessidade de licitação [7]. Visando ampliar o alcance do programa, o Decreto no 8.473 , de 22 de junho de 2015, torna obrigatório, a partir de 2016, a aquisição de gêneros alimentícios de agricultores familiares e suas organizações para o abastecimento das instituições públicas com administração federal [8]. Dessa forma observa-se que há estímulos legais e organizativos para que a compra da agricultura familiar seja daquela situada próxima dos locais de consumo. Desde sua implantação, a modalidade já beneficiou quatro mil agricultores, que venderam mais de $\mathrm{R} \$ 66,4$ milhões em produtos [?].

A criação do PAA representou um importante marco para a agricultura familiar no país, uma vez que o programa surge com um regulamento público que protege o produto da agricultura familiar da concorrência desigual do mercado [10]. Além disso, é oportuno salientar que, ao garantir o mercado institucional de alimentos para a agricultura familiar, as compras institucionais passam a desempenhar uma tripla função para a SAN: atendimento a populações em insegurança alimentar e nutricional, fortalecimento da agricultura familiar e estímulo ao desenvolvimento de sistemas produtivos localizados.

Estima-se que tais políticas públicas vêm auxiliando na redução da pobreza e na modernização dos estratos menos estruturados da agricultura familiar, inseridos em contextos territoriais também vulneráveis [11-13], colaboram positivamente com a produção sustentável e a preservação ambiental [14]. Elas também contribuem para a melhoria da qualidade da alimentação fornecida em instituições públicas [15-22], sendo isto reconhecido como um dos fatores pelo qual o país ficou fora do mapa da fome em 2014 [23].

Dentre os equipamentos públicos com demanda regular de alimentos, cabe destacar a relevância dos Restaurantes Universitários (RU), frente ao atendimento diário de alunos nas mais de 130 universidades estaduais e federais brasileiras [24], o que sugere a potencialidade desses equipamentos no desenvolvimento da agricultura familiar e dos territórios locais onde estão inseridos.

Contudo, evidenciam-se barreiras para a efetivação da compra institucional de alimentos da agricultura familiar. A complexidade da distribuição dos produtos ${ }^{[25,26]}$ e a regularidade de oferta ${ }^{[21]}$ representam as principais barreiras para a comercialização da produção familiar junto aos mercados institucionais. Tal situação torna-se mais relevante diante da complexidade do processo produtivo de refeições de uma Unidade de Alimentação e Nutrição (UAN), responsável pela oferta de uma alimentação equilibrada nutricionalmente, segura do ponto de vista higiênicosanitário e sensorialmente adequada [27].

A opção por adquirir alimentos da agricultura familiar próxima territorialmente, exige mudanças no processo produtivo de refeições, principalmente no planejamento de cardápios e no sistema de abastecimento da UAN. Nesse sentido, Soares et al. [28] aponta que para o sucesso no fornecimento de alimentos da agricultura familiar é imprescindível que o levantamento da demanda se dê articulado com o mapeamento e organização da produção agrícola, ambos previamente à elaboração dos cardápios. Assim, torna-se possível harmonizar a oferta com a demanda de alimentos, orientando a produção agrícola, garantindo a regularidade de entrega dos produtos e a inclusão dos alimentos produzidos localmente nos cardápios.

Neste contexto, para o êxito da articulação entre a produção local/regional dos agricultores familiares e a demanda institucional de alimentos, tornase necessário conhecer as especificidades desse mercado, as possibilidades e as barreiras para $\mathrm{o}$ fornecimento de alimentos. De acordo com o exposto e visando o desenvolvimento de sistemas agroalimentares localizados, assim como a garantia da Segurança Alimentar e Nutricional, o objetivo desse artigo foi analisar a potencialidade da compra institucional de alimentos de um Restaurante Universitário (RU) do Sul do Brasil para a promoção de sistemas sustentáveis e localizados.

\section{MATERIAL E MÉTODOS}

A pesquisa de campo se realizou por meio de um estudo observacional exploratório, no Restaurante Universitário (RU) de uma Universidade Federal do Sul do Brasil. O estudo é observacional, pois se procurou intervir o mínimo possível no evento pesquisado e é exploratório, pois é realizada a investigação inicial para somente depois teorizar acerca dos resultados.

A escolha pelo local de estudo ocorreu por conveniência. O RU selecionado funciona diariamente, incluindo sábados, domingos e feriados, no almoço e no jantar. De segunda a sexta-feira são elaborados aproximadamente 7.000 almoços e 2.000 jantares, e nos finais de semana aproximadamente 1.500 refeições no almoço e 600 no jantar. Para isso, o restaurante dispõe 
de 44 servidores federais e 106 terceirizados, completando um total de 150 trabalhadores com diferentes funções, desde administrativas até serviços de segurança.

A gestão e a operacionalização do processo produtivo de refeições ficam a encargo dos três nutricionistas do restaurante, os quais periodicamente elaboram os cardápios e as listas de compras, de acordo com a disponibilidade de equipamentos, custo e variedade de alimentos. No que se relaciona à estrutura física para o preparo das refeições, o restaurante conta com as seguintes áreas: recebimento; almoxarifado; câmeras frias; pré-preparo de carnes; pré-preparo de vegetais; preparo (seleção de feijão; preparo de sobremesas; cocção; higienização de utensílios da produção; higienização de utensilios dos comensais (copa); manutenção de temperatura); distribuição; refeitório; vestiários; lavanderia. Salienta-se que os espaços de trabalho são relativamente pequenos para comportar a produção diária das nove mil refeições.

Para a realização do estudo foram analisadas as listas de compra de alimentos de novembro de 2012 a abril de 2013. Devido englobar o período de férias, o número de dias de funcionamento do restaurante foi diferente nos meses analisados: 30 dias em novembro/2012; 22 dias em dezembro/2012; 20 dias em fevereiro/2013; 31 dias em março/2013; e 30 dias em abril/2013.

A análise se deu a partir da identificação das quantidades mensais e as variedades dos alimentos adquiridos, agrupados segundo a forma de produção (orgânico/convencional) e de apresentação (grau de processamento). Para tal, foram extraídos dados referentes à quantidade, às unidades de medida e à descrição (forma de apresentação, grau de processamento e forma de produção) dos alimentos adquiridos.

As informações sobre as unidades de compra dos produtos e o peso das embalagens apresentados nas listas de compras foram utilizados para a padronização, em quilograma, das quantidades adquiridas de todos os alimentos.

Para a análise dos dados, os alimentos presentes nas listas de compras foram agrupados em 20 categorias, considerando as características nutricionais, sensoriais e técnicas de preparo, conforme apresentado no Quadro 1. Posteriormente, dentro de cada categoria, os alimentos foram subdivididos conforme a forma de produção orgânica e convencional, e conforme o grau de processamento. 
Quadro 1. Categorias utilizadas para a análise das listas de compras.

\begin{tabular}{|c|c|}
\hline Categoria & Características \\
\hline Frutas & Frutas frescas e suco natural \\
\hline Hortaliças - Grupo 1 ao 7 [29] & $\begin{array}{l}\text { Grupo } 1 \text { - Flores com 5\% de carboidrato } \\
\text { Grupo } 2 \text { - Folhas, caules e brotos com } 5 \% \text { de carboidrato } \\
\text { Grupo } 3 \text { - Frutos, raízes, tubérculos com até } 10 \% \text { de carboidrato } \\
\text { Grupo } 4 \text { - Raízes e tubérculos com até } 10 \% \text { de carboidrato } \\
\text { Grupo } 5 \text { - Bulbos com até } 10 \% \text { de carboidrato } \\
\text { Grupo } 6 \text { - Raízes, tubérculos e frutos com } 20 \% \text { de carboidrato } \\
\text { Grupo } 7 \text { - Ervas, especiarias e vegetais complementares }\end{array}$ \\
\hline Cereais, pães, massas, farinhas e fermentos & Cereal matinal sem açúcar, pão, macarrão, farinha de trigo e milho, fermentos \\
\hline Leguminosas & Todas as leguminosas in natura \\
\hline $\begin{array}{l}\text { Carnes in natura, ovos, embutidos e produtos cárneos } \\
\text { industrializados }\end{array}$ & $\begin{array}{l}\text { Cortes bovinos, suínos, aves e peixes sem processamento, ovos, almôndega, } \\
\text { quibe, linguiça, bolinho de peixe }\end{array}$ \\
\hline Leite e derivados & Todos os tipos de leite, ricota, queijo, iogurte natural \\
\hline $\begin{array}{l}\text { Temperos utilizados em pequenas quantidades nas } \\
\text { preparações }\end{array}$ & Vinagre, aceto balsâmico, azeite de oliva \\
\hline Molhos com alto teor de sódio e/ou gordura saturada & $\begin{array}{l}\text { Creme de leite, manteiga, margarina, maionese, gordura vegetal hidrogenada, } \\
\text { queijos e grande quantidade de óleo adicionado }\end{array}$ \\
\hline $\begin{array}{l}\text { Alimentos processados com alto teor de açúcar e/ou } \\
\text { sódio }\end{array}$ & $\begin{array}{l}\text { Doce de fruta, geleia, cremes doces, iogurte, biscoitos doces, barra de cereais, } \\
\text { bolo com recheio, cereais adoçados }\end{array}$ \\
\hline Alimentos concentrados, em pó ou desidratados & Em pó ou desidratados e misturas para o preparo de alimentos \\
\hline Enlatados e conservas & Todos os alimentos enlatados ou em conserva. \\
\hline Óleo e azeite & Óleo de soja, girassol, canola, milho \\
\hline Sal & Grosso, fino, temperado \\
\hline
\end{tabular}

Ressalta-se que grande parte dos alimentos, principalmente hortaliças, frutas e carnes, são adquiridos com algum grau de processamento, tendo em vista o espaço reduzido da área de preparo e prépreparo em relação ao número de refeições servidas diariamente. Investigou-se a aquisição de produtos alimentícios brutos (matéria-prima não processada, que precisa de pré-preparo e preparo) e produtos alimentícios pré-prontos ou prontos para utilização. Desta forma, os alimentos também foram classificados conforme seu grau de processamento. Para as frutas e hortaliças foi utilizada a divisão: 1 . sem processamento; 2. higienizado; 3. higienizado e cortado; 4. higienizado, descascado e cortado. Já para as carnes e produtos cárneos: 1. sem processamento; 2. com algum nível de processamento; e 3. embutidos e produtos cárneos processados.
Para análise sobre as quantidades totais foi considerada a proporção de cada categoria em relação ao total de alimentos. Para a análise das quantidades de alimentos orgânicos e aqueles com algum grau de processamento, considerou-se também a proporção em relação ao total da categoria em questão (ex: proporção do total de frutas orgânicas em relação ao total de frutas adquiridas). A digitação e a análise descritiva dos dados foram realizadas com auxílio de planilhas eletrônicas.

\section{RESULTADOS}

As quantidades e as variedades dos alimentos adquiridos em cada mês analisado, assim como o percentual que cada categoria de classificação representou em relação ao total adquirido no período estão expostas na Tabela 1. Os dados apresentados evidenciam o grande potencial de compra do restaurante estudado, com uma média mensal de 77 
toneladas $(t)$ e quase $400 t$ de alimentos adquiridos no período avaliado. As hortaliças, seguidas das carnes e das frutas, foram os mais adquiridos, somando juntos aproximadamente 280 toneladas.

Tabela 1. Variedade e quantidade de alimentos mensais adquiridos pelo RU estudado, por grupo de alimentos, e percentual de cada grupo em relação ao total geral adquirido nos cinco meses.

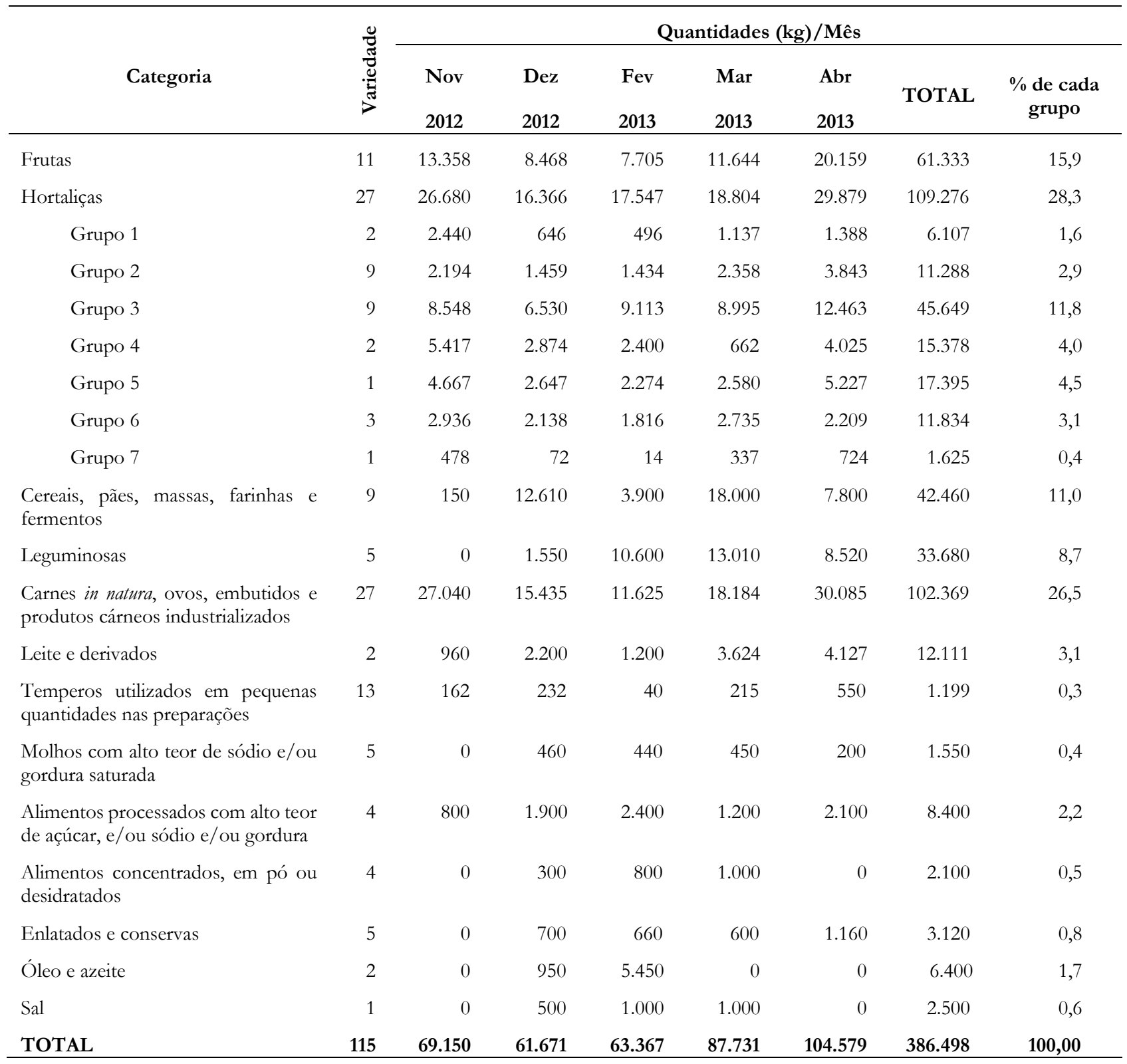

Observou-se a aquisição de 11 variedades de frutas, as quais totalizaram $61,3 \mathrm{t}$. As frutas adquiridas no período foram: maçã gala nacional $(24 \%)$, laranja pera $(22 \%)$, banana $(21 \%)$, poncã $(10 \%)$, abacaxi $(7 \%)$, salada de frutas (mistura de maçã, mamão, abacaxi e melão picados) (5\%), kiwi (4\%), morango (3\%), mamão formosa $(2 \%)$, melão $(2 \%)$ e limão tahiti (orgânico e convencional) (1\%). 
No período estudado, foram adquiridas 109,3 toneladas de hortaliças, 27 variedades, representando quase $30 \%$ do total de alimentos. Considerando individualmente a categoria das hortaliças, observou-se que o grupo 3 (ver distribuição de grupos para todos os produtos, no Quadro 01), referente aos frutos, raízes, tubérculos com até $10 \%$ de carboidratos, representou a maioria (45,6t), seguido do grupo $5(17,4 \mathrm{t})$ e do grupo 4 $(15,4 \mathrm{t})$ (Tabela 1). O tomate representou $60 \%$ da quantidade adquirida do grupo, seguido da vagem e abobrinha (ambas com 8\%) e abóbora (7\%). Percentuais menores foram observados para chuchu, berinjela, pepino, pimentão verde e rabanete. A cebola foi o único alimento do grupo 5 e no grupo 4 foram encontrados cenoura (75\%) e beterraba. O grupo 2 foi composto por 9 tipos de hortaliças folhosas, sendo que a alface (orgânica e convencional) representou 33\% da quantidade total adquirida, seguido do repolho $(29 \%)$, rúcula $(11 \%)$, couve folha orgânica e convencional $(10 \%)$, acelga ( $8 \%$ ), agrião e chicória (4\% cada) e menos de $1 \%$ de espinafre e escarola.

A quantidade de produtos adquiridos na categoria de carnes in natura, ovos, embutidos $\mathrm{e}$ produtos cárneos industrializados representou uma aquisição de 102,4t, estando composto por 27 variedades. Entre eles, a carne bovina representou o maior percentual (28\%), seguida das aves e ovos $(25 \%)$, suínos $(12 \%)$ e frutos do mar (11\%). Os embutidos e produtos cárneos industrializados representaram menor percentual, sendo $8 \%$ derivados de frutos do mar (peixe empanado e bolinho de peixe), $8 \%$ bovinos (almôndega, charque, quibe), $7 \%$ aves (filé de peito empanado, peito recheado e empanado, sobrecoxa empanada) e 1\% suíno (linguiça calabresa).
A Tabela 2 demonstra a quantidade e as variedades de frutas, hortaliças e carnes adquiridas, segundo o grau de processamento exigido nas especificações de compra do RU estudado. Os resultados revelam que a maior quantidade de frutas estava sendo adquirida sem processamento (78\%), enquanto $100 \%$ das hortaliças apresentaram algum grau de processamento, com destaque para a higienização e cortes. Os principais cortes para as hortaliças eram: cubos, ralado, tiras, rodelas, palitos, fino (para folhosos) e florete. 
Tabela 2. Grau de processamento das frutas, hortaliças e carnes solicitadas pelo RU estudado.

\begin{tabular}{|c|c|c|c|c|}
\hline Processamento & Variedades & $\begin{array}{l}\text { Variedades } \\
(\mathrm{n})\end{array}$ & $\begin{array}{l}\text { Quantidade } \\
\qquad(\mathrm{kg})\end{array}$ & $\begin{array}{l}\text { Percentual } \\
\text { (\%) }\end{array}$ \\
\hline \multicolumn{5}{|c|}{ Frutas } \\
\hline Sem processamento & Banana, maçã, laranja, poncã, limão & 5 & $47.845,25$ & $78,00 \%$ \\
\hline Somente higienizado & Morango & 1 & $1.760,00$ & $2,90 \%$ \\
\hline $\begin{array}{l}\text { Higienizado, descas- } \\
\text { cado e cortado }\end{array}$ & Abacaxi, kiwi, mamão, salada de fruta e melão & 5 & $11.728,00$ & $19,10 \%$ \\
\hline Total & & 11 & $61.333,25$ & $100,00 \%$ \\
\hline \multicolumn{5}{|c|}{ Hortaliças } \\
\hline Somente higienizado & Alface, espinafre, escarola & 3 & $3.859,00$ & $3,50 \%$ \\
\hline Higienizado e cortado & $\begin{array}{l}\text { Brócolis, couve flor, acelga, agrião, chicória, couve folha, } \\
\text { repolho, rúcula, berinjela, abóbora, abobrinha, pepino, } \\
\text { pimentão verde, rabanete, tomate, vagem }\end{array}$ & 16 & $58.471,00$ & $53,50 \%$ \\
\hline $\begin{array}{l}\text { Higienizado, descas- } \\
\text { cado e cortado }\end{array}$ & $\begin{array}{l}\text { Chuchu, cenoura, beterraba, cebola, batata inglesa e } \\
\text { cheiro-verde, aipim e batata doce }\end{array}$ & 8 & $46.946,00$ & $43,00 \%$ \\
\hline Total & & 27 & $109.276,00$ & $100,00 \%$ \\
\hline \multicolumn{5}{|c|}{ Carnes } \\
\hline \multirow[t]{2}{*}{ Sem processamento } & Suína: lombinho, pernil & & & \\
\hline & $\begin{array}{l}\text { Aves: coxa e sobrecoxa de frango, peito de peru in } \\
\text { natura, peito de frango }\end{array}$ & 5 & $23.611,50$ & $23,10 \%$ \\
\hline \multirow{3}{*}{$\begin{array}{l}\text { Com algum nível de } \\
\text { processamento: picado, } \\
\text { bife, iscas, moído }\end{array}$} & $\begin{array}{l}\text { Bovina: patinho em cubos e em iscas, lagarto em fatias, } \\
\text { coxão duro moído, coxão mole em bifes }\end{array}$ & \multirow{3}{*}{11} & \multirow{3}{*}{$54.752,00$} & \multirow{3}{*}{$53,50 \%$} \\
\hline & $\begin{array}{l}\text { Suína: bisteca } \\
\text { Aves: filé de peito de frango, sassami }\end{array}$ & & & \\
\hline & $\begin{array}{l}\text { Frutos do mar: filé de peixe e peixe em posta; camarão } \\
\text { rosa descascado }\end{array}$ & & & \\
\hline \multirow[t]{3}{*}{$\begin{array}{l}\text { Embutidos e produtos } \\
\text { cárneos industrializa- } \\
\text { dos }\end{array}$} & $\begin{array}{l}\text { Bovina: charque, quibe, almôndega bovina } \\
\text { Suína: linguiça calabresa }\end{array}$ & \multirow{3}{*}{9} & \multirow{3}{*}{$24.005,00$} & \multirow{3}{*}{$23,40 \%$} \\
\hline & $\begin{array}{l}\text { Aves: filé de peito de frango empanado, peito de frango } \\
\text { recheado empanado, sobrecoxa empanada }\end{array}$ & & & \\
\hline & $\begin{array}{l}\text { Frutos do mar: filé de peixe empanado, bolinho de peixe } \\
\text { cozido empanado }\end{array}$ & & & \\
\hline Total & & 25 & $102.368,50$ & $100,00 \%$ \\
\hline
\end{tabular}

A exigência de algum grau de processamento também foi observada para mais da metade das carnes adquiridas. A etapa de porcionamento era exigida do fornecedor para aproximadamente $67 \%$ da quantidade total adquirida. Os principais cortes para as carnes eram: bifes, cubos, iscas, fatias, moído, filé e posta de peixe. Para os produtos cárneos, os processos de porcionar (cortar em porções pré-estabelecidas) e de empanar foram os mais observados.

$\mathrm{Na}$ Tabela 3 é possível observar as categorias de alimentos que apresentavam alguma variedade orgânica e o percentual em relação ao total de alimentos da categoria. Observou-se a aquisição de quase 20 toneladas de alimentos orgânicos, divididos em 13 
variedades pertencentes às categorias frutas, hortaliças $\mathrm{e}$ carnes. Ressalta-se que todas as variedades de alimentos orgânicos foram adquiridas também na forma convencional.

Tabela 3. Total de alimentos de produção convencional e orgânica comprados pelo RU.

\begin{tabular}{|c|c|c|c|c|c|c|}
\hline \multirow[b]{2}{*}{ Categoria } & \multicolumn{2}{|c|}{ Convencional } & \multicolumn{2}{|c|}{ Orgânico } & \multirow{2}{*}{$\begin{array}{l}\text { Quantidade } \\
\text { total (kg) }\end{array}$} & \multirow{2}{*}{$\begin{array}{c}\text { Variedades } \\
\text { orgânicas (n) }\end{array}$} \\
\hline & $\begin{array}{l}\text { Quantidade } \\
\text { (kg) }\end{array}$ & $\%$ & $\begin{array}{l}\text { Quantidade } \\
\text { (kg) }\end{array}$ & $\%$ & & \\
\hline Frutas & 61.183 & 99,8 & 150 & 0,2 & 61.333 & 1 \\
\hline Hortaliças - Grupo 2 & 8.724 & 77,3 & 2.564 & 22,7 & 11.288 & 3 \\
\hline Hortaliças - Grupo 3 & 44.486 & 97,5 & 1.163 & 2,5 & 45.649 & 2 \\
\hline Hortaliças - Grupo 4 & 10.715 & 69,7 & 4.663 & 30,3 & 15.378 & 2 \\
\hline Hortaliças - Grupo 6 & 8.084 & 68,3 & 3.750 & 31,7 & 11.834 & 2 \\
\hline Hortaliças - Grupo 7 & 1.459 & 89,8 & 166 & 10,2 & 1.625 & 1 \\
\hline $\begin{array}{l}\text { Carnes in natura, ovos, } \\
\text { embutidos e produtos } \\
\text { cárneos industrializa- } \\
\text { dos }\end{array}$ & 95.059 & 92,9 & 7.310 & 7,1 & 102.369 & 2 \\
\hline Total & 229.710 & 92,1 & 19.766 & 7,9 & 249.476 & 13 \\
\hline
\end{tabular}

As hortaliças orgânicas do grupo 2 (folhosas) apresentaram três variedades (alface, couve folha $\mathrm{e}$ repolho), totalizando 2,6 toneladas para os cinco meses. Do grupo 4 foi adquirida a maior quantidade de orgânicos entre as hortaliças, 2,9t de cenoura e 1,8t de beterraba. Entre as hortaliças, os grupos 1 e 5 não apresentaram nenhuma variedade orgânica.

De maneira complementar tem-se que 11,3\% (12,3 toneladas) das hortaliças compradas nos cinco meses eram orgânicas (Figura 1), correspondendo aos alimentos: cheiro verde, alface, couve folha, repolho, chuchu, abobrinha, cenoura, beterraba, aipim e batata doce. Quanto às frutas, $0,2 \%$ eram orgânicas (limão tahiti). Entre as carnes, peito, coxa e sobrecoxa de frango tinham variedades de produção orgânica, que perfizeram 7,1\% do total de carne adquirida nos cinco meses estudados. Considerando o total de alimentos adquiridos no período, 5\% foram produzidos de maneira orgânica. 
Figura 1. Percentual de frutas, hortaliças e carnes orgânicas compradas em relação ao total de cada categoria e geral.

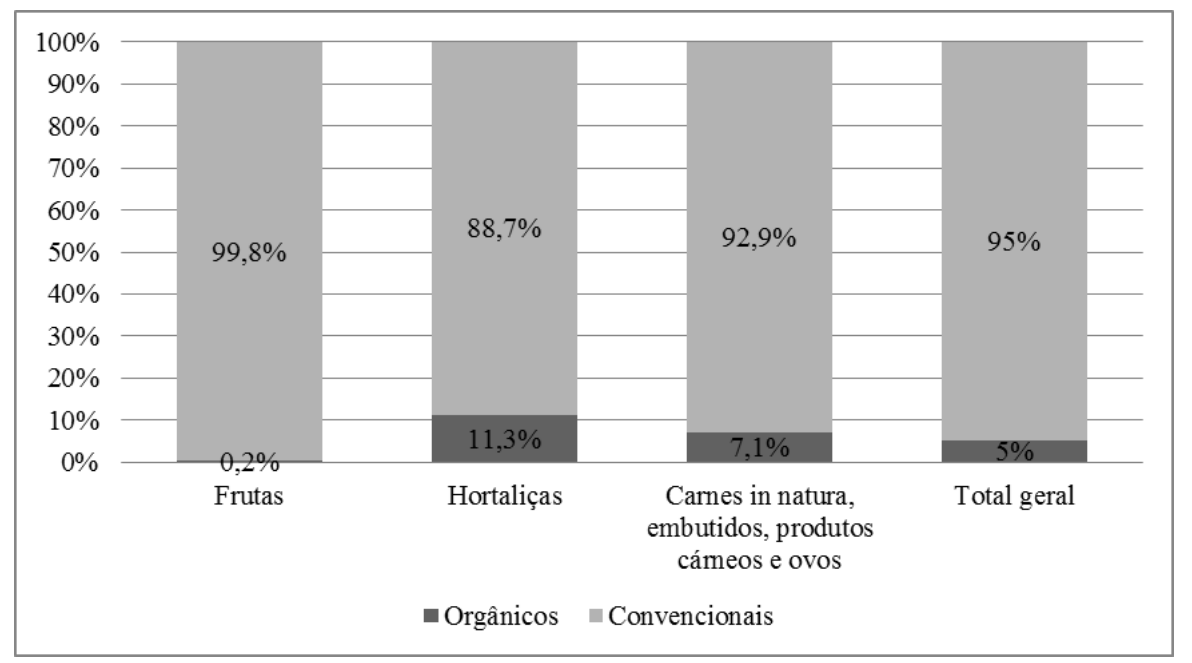

\section{DISCUSSÃO}

A pesquisa identificou as especificidades da demanda de alimentos do RU, evidenciando o potencial das compras públicas realizadas, como um importante mercado para a comercialização dos produtos da agricultura familiar. Entre os alimentos adquiridos, o grupo das hortaliças se destacou com o maior quantitativo de compra, contudo a totalidade desses alimentos estava sendo adquirida com algum grau de processamento. Observou-se a preocupação com a qualidade dos alimentos e com a sustentabilidade ambiental a partir da aquisição de alimentos orgânicos, mesmo que com pouca representação no total geral adquirido.

A comercialização de alimentos junto às instituições públicas vem sendo apontada como oportuna para o fortalecimento da agricultura familiar, a exemplo do que vem ocorrendo desde a implementação do PAA [22, 31, 32] e da vinculação do abastecimento do PNAE com a produção familiar [26, 33]. Tal oportunidade se acentua frente ao grande volume de alimentos básicos adquiridos pelo RU, tais como frutas, leguminosas, cereais, carnes e hortaliças, uma vez que estudos anteriores apontam que esses alimentos representam os produtos mais produzidos pela agricultura familiar [3].

Contudo, no RU estudado observou-se que a totalidade das hortaliças e parte das frutas e das carnes, estavam sendo adquiridas com algum grau de processamento, comumente denominados de alimentos minimamente processados (MMP) ${ }^{1}$. A opção de compra desses alimentos se deu principalmente pela estrutura física insuficiente para o preparo do número de refeições necessárias para o atendimento do público da universidade. Dessa forma, transferem-se aos fornecedores algumas etapas que seriam realizadas no próprio restaurante.

A utilização de alimentos MMP apresenta-se como uma inovação no setor da produção de refeições em termos de produtos alimentícios [35]. Ao utilizar esses alimentos é possível o controle e redução do custo de fabricação na UAN, além de garantir parâmetros de qualidade para a aquisição dos alimentos. Com a tendência dessas UANs compraremalimentos MMP, as indústrias agroalimentares assumem parte das tarefas da produção de alimentos, como o pré-preparo (descascamento, limpeza e/ou corte). 
Se, por um lado, a aquisição desses produtos pode representar uma facilidade para o restaurante, por outro, pode se transformar em uma barreira para a comercialização da produção familiar, diante da falta de estrutura por parte das agroindústrias familiares para o processamento desses alimentos [9, 26, 36]. Neste contexto, Sabourin [9] destaca que o acesso a mercados adaptados às características da agricultura familiar ainda é uma das grandes dificuldades do setor. A opção de produzir alimentos MMP exige dos produtores investimentos em equipamentos especiais de corte, centrífugas, produtos sanitizantes, embalagens específicas, além de um sistema de transporte refrigerado e um sistema eficiente de entrega [37].

Nesse sentido, as especificações do mercado institucional do RU estudado podem limitar a participação das unidades produtivas familiares no fornecimento de alimentos. Essa questão agrava-se devido à complexidade das exigências legais e sanitárias para o processamento e comercialização de alimentos [38, 39] e pela dificuldade dos produtores familiares se adequarem a essas exigências [37], o que sugere a necessidade de regulações específicas da qualidade dos alimentos relativa à produção de baixa escala ${ }^{[39]}$.

O processamento não deve representar um fator de exclusão para a agricultura familiar, mas sim uma oportunidade crescente de mercado, gerando benefícios econômicos para os produtores, frente à agregação de valor proporcionada pela agroindustrialização ${ }^{[40]}$. Nesse contexto e visando a superação das barreiras para o processamento e comercialização dos alimentos, reconhece-se a necessidade de políticas de incentivo à organização dos agricultores e dos demais elos da cadeia, auxiliando no desenvolvimento de iniciativas de fornecimento local e certificação participativa, melhorando a renda dos envolvidos e garantindo segurança para os consumidores finais ${ }^{[37}$. Por meio das cooperativas e das associações, os agricultores podem ter mais facilidade de acessar os mercados institucionais, os quais se tornam uma oportunidade para a estruturação dessas organizações.

Políticas para o desenvolvimento de iniciativas de fornecimento local, pelos agricultores familiares, podem estimular sua organização cooperativa, assim como podem auxiliar na aquisição de maquinários para a produção de alimentos MMP. A tendência de mercado que aponta a crescente demanda por alimentos MMP [35, 41] será mais bem aproveitada por quem estiver mais preparado ou receber mais apoio. Ao contrário, desde sua origem o PAA tem contribuído para viabilizar um mercado aos agricultores familiares em condições mais vulneráveis, menos especializados, normalmente inseridos em territórios também socioeconomicamente vulneráveis. Neste sentido, mercados que estimulem o desenvolvimento de sistemas produtivos localizados (SPL) ou sistemas agroalimentares localizados (SIAL), revelam o potencial de ir além da esfera comercial e produtiva, estimulando a integração, organização e o desenvolvimento territorial. Estimulando os SPL e os SIAL se favorecem as redes sociais locais e sua identificação com o território, promovendo uma dinamização socioeconômica de cunho endógeno [42].

Em adição, deve-se considerar que a crescente busca por alimentos com denominação de origem e proveniente de formas sustentáveis de produção [41], coloca a agricultura familiar em posição de vantagem no mercado, ante aos aspectos próprios da produção, os quais se transformam em atributos de qualidade, e consequentemente com maior valor de mercado [43].

Além de representar potencial influência no mercado de produtos da agricultura familiar, o RU, por meio do expressivo volume de alimentos adquiridos pode reduzir o impacto social e ambiental atentando para a forma com que os alimentos são produzidos [44]. As UAN vinculadas a espaços educativos assumem importante papel pedagógico e na construção concreta dos sistemas agroalimentares, ao se apresentarem diariamente no setor de varejo e consumo, fazendo escolhas diárias em nome de milhares de consumidores [45, 46]. Visando minimizar os impactos ambientais e sociais gerados pelos processos produtivos, o estabelecimento de critérios para a aquisição de alimentos em UAN vem sendo amplamente discutido [47].

No caso estudado observou-se a preocupação do restaurante com a sustentabilidade ambiental, frente ao estabelecimento de critérios de compra que consideraram as formas de produção dos alimentos, uma vez que parte deles era proveniente da produção orgânica. Apesar de incipiente quando comparado com a quantidade total, a aquisição de $20 \mathrm{t}$ de alimentos orgânicos durante os cinco meses estudados é relevante para o desenvolvimento desse mercado e vai ao encontro das diretrizes da Política Nacional de Agroecologia e Produção Orgânica (Pnapo) e da Lei Orgânica de Segurança Alimentar e Nutricional. Tais diretrizes apontam para a importância do estímulo à produção de alimentos orgânicos e de base 
agroecológica para a promoção da soberania e segurança alimentar e nutricional, e do direito humano à alimentação adequada e saudável [48, 49]. Isso porque o método de produção orgânica garante melhor qualidade de vida aos trabalhadores rurais, menores riscos de contaminação, maior conservação do ambiente ${ }^{[50,51]}$ e melhor qualidade nutricional dos alimentos [52], com praticamente os mesmos rendimentos obtidos nas formas convencionais de produção quando adotadas práticas agroecológicas [53].

O RU estudado estimulou a agroecologia e a sustentabilidade, quando operou a compra efetiva de alimentos orgânicos, assim como quando indicou o interesse de comprá-los, na medida em que isto contribui para a ampliação da produção deste tipo de alimento. Contudo, cabe comentar que estudos anteriores vêm apontando dificuldades para aquisição institucional de alimentos orgânicos [28, 54, 55], dentre as quais se destaca a baixa disponibilidade de produtos certificados, assim como a limitação logística de processamento e comercial pelos produtores familiares [55]. Nesse contexto, pode-se inferir que diante de uma maior disponibilidade, poderia haver uma maior aquisição desses alimentos pelo restaurante, o que reforça a necessidade da busca por alternativas viáveis para a superação de barreiras que vão além daquelas próprias aos sistemas de produção.

A partir do estabelecimento de critérios de compra, aliado à adaptação dos cardápios, as UANs podem incentivar formas mais sustentáveis de produção, priorizando a compra de alimentos orgânicos, sazonais e produzidos próximos à unidade de consumo, provenientes da agricultura familiar agroecológica $[44,45,56,57]$. No que se refere aos mercados institucionais, esse processo vem sendo estimulado no Brasil por meio da implementação de políticas públicas direcionadas à garantia de mercado para a agricultura familiar, o que se observa pela instituição do Programa de Aquisição de Alimentos em 2003, da obrigatoriedade de aquisição de alimentos da agricultura familiar para o abastecimento do Programa Nacional de Alimentação Escolar em 2009 e, mais recentemente, em 2012, da modalidade de "Compra Institucional" do PAA. Tais programas facilitam o abastecimento institucional com alimentos provenientes da agricultura familiar, dispensando a realização de licitação, uma vez que ela dificulta a inserção da produção familiar [58]. Tal dificuldade se evidencia frente à concorrência com mercados varejistas globais, que apresentam posição privilegiada e práticas dominantes de mercado [59].
Contudo, estudos indicam que importante parcela dos municípios brasileiros não está em consonância com as políticas federais de fomento à aquisição local de alimentos da agricultura familiar [00,61], sugerindo que são necessárias complementações dessas políticas, que gerem ações operacionais, onde os equipamentos públicos (restaurantes universitários, escolas, restaurantes populares, entre outros) efetivamente criem um processo de diálogo com a agricultura familiar do seu território e potencializem seu desenvolvimento.

O presente estudo demonstrou o grande potencial das UANs institucionais para promoção de sistemas agroalimentares locais, caso consigam ampliar seu volume de compra e facilitar as condições de venda por parte da agricultura familiar do seu entorno. A aquisição de alimentos de produção familiar pode gerar benefícios, tanto para produtores como para consumidores. Possibilitaria a inclusão de mais agricultores familiares neste mercado e consequentemente o fortalecimento desse seguimento produtivo [22, 31, 32], ao mesmo tempo que pode proporcionar melhorias na qualidade da alimentação das instituições [15-19].

A implementação do PAA exige articulação entre produção e consumo, de forma a estruturar um cronograma de produção e entrega, atendendo ao mesmo tempo as necessidades dos produtores e dos consumidores [25]. Os responsáveis pela compra devem proceder à identificação dos alimentos produzidos na região e com potencial para o atendimento da demanda, previamente à elaboração dos cardápios [2]. É fundamental que o planejamento e a execução das compras integrem as organizações de agricultores, fortalecendo estas organizações para sua estruturação, possibilitando o atendimento das especificidades da demanda institucional, como a produção de alimentos MMP e orgânicos.

A realização de estudo de caso em apenas um restaurante universitário da região Sul do Brasil é reconhecida como uma limitação do estudo, com restrita capacidade de inferências. Contudo, salienta-se o rigor metodológico utilizado, o qual permite chegar a conclusões importantes para a área. Ademais, os dados do presente estudo demonstraram o potencial do RU na aquisição da agricultura familiar. A partir disso e considerando o número de restaurantes universitários do Brasil, pode-se inferir o impacto potencial das compras institucionais para o desenvolvimento de sistemas agroalimentares locais e sustentáveis. 


\section{CONCLUSÃO}

O presente estudo revelou a potencialidade das compras realizadas para o abastecimento do restaurante universitário no fomento de sistemas agroalimentares localizados e sustentáveis, diante da demanda mensal de $77 \mathrm{t}$ de alimentos, sendo $10 \mathrm{t}$ de frutas sem processamento e $22 \mathrm{t}$ de hortaliças minimamente processadas. Além disso, representa a possibilidade de aquisição de alimentos provenientes da agricultura familiar produzidos na região e com bases agroecológicas.

O fornecimento de alimentos pelo PAAinstitucional representa um importante mecanismo de promoção da sustentabilidade, mediante o estímulo a formas agroecológicas de produção, e de fortalecimento da agricultura familiar, tendo em vista a relativa estabilidade deste mercado. Contudo, a necessidade de processamento de importante parte dos alimentos adquiridos pelo restaurante representa uma barreira para o fornecimento pelos agricultores familiares, a qual pode ser superada com políticas e ações para estruturação das organizações dos agricultores.

Para que haja sucesso da articulação entre a produção familiar e a compra institucional tornam-se necessárias novas formas de planejamento da produção e do processamento dos alimentos, assim como da organização do processo produtivo de refeições, com o envolvimento e a ação articulada dos diversos agentes, desde a produção agrícola até o consumo dos alimentos. Por isso, realizar estudos para identificar a demanda, conforme apresentado, bem como mapear a produção local para inserir os alimentos já produzidos no cardápio, são importantes estratégias para o sucesso da Compra Institucional.

\section{AGRADECIMENTOS}

Aos nutricionistas do Restaurante Universitário estudado, à Pró-Reitoria de Extensão da Universidade Federal de Santa Catarina pelas bolsas de extensão concedidas e ao Conselho Nacional de Desenvolvimento Científico e Tecnológico (CNPq) pelo apoio financeiro por meio da Chamada MCTI/Ação Transversal-LEI/CNPq no 82/2013.

\section{REFERÊNCIAS}

[1] Food and Agriculture Organization - FAO. International Year of Family Farming, 2014. Rome: 66th session; 2011.

[2] Brasil, Ministério da Educação e Ministério do Desenvolvimento Agrário. O encontro da agricultura familiar com a alimentação escolar. Brasília (DF); 2009.

[3] Food and Agriculture Organization - FAO, Banco Interamericano de desenvolvimento - BID. Políticas para la agricultura familiar en América Latina y el Caribe. Santiago: Oficina Regional de la FAO para América Latina y el Caribe; 2007.

[4] Lowder SK, Skoet J, Singh S. What do we really know about the number and distribution of farms and family farms in the world? Background paper for The State of Food and Agriculture. ESA Working Paper. Rome: FAO; 2014.

[5] Brasil. Lei no 11.947, de 16 de junho de 2009. Dispõe sobre o atendimento da alimentação escolar e do Programa Dinheiro Direto na Escola aos alunos da educação básica; altera as Leis no 10.880, de 9 de junho de 2004, 11.273, de 6 de fevereiro de 2006, 11.507, de 20 de julho de 2007; revoga dispositivos da Medida Provisória no 2.178-36, de 24 de agosto de 2001, e a Lei no 8.913, de 12 de julho de 1994; e dá outras providências. Diário Oficial da União. 17 set 2009.

[6] Brasil. Decreto no 7.775, de 4 de julho de 2012. Regulamenta o Art. 19 da Lei no 10.696, de 2 de julho de 2003, que institui o Programa de Aquisição de Alimentos, e o Capítulo III da Lei no 12.512 , de 14 de outubro de 2011, e dá outras providências. Diário Oficial da União. 05 jul 2012.

[7] Brasil. Resolução no 50, de 26 de setembro de 2012. Dispõe sobre a sistemática de funcionamento da modalidade de execução Compra Institucional, no âmbito do Programa de Aquisição de Alimentos da Agricultura Familiar - PAA. Diário Oficial da União. 27 set 2012.

[8] Brasil. Decreto no 8.473, de 22 de junho de 2015. Estabelece, no âmbito da Administração Pública Federal, o percentual mínimo destinado à aquisição de gêneros alimentícios de agricultores familiares e suas organizações, empreendedores familiares rurais e demais beneficiários da Lei no 11.326, de 24 de julho de 2006, e dá outras providências. Diário Oficial da União. 2015. 23 jun 2015. 
[9] Brasil. Ministério do Desenvolvimento Social e Combate à Fome. Compra Institucional amplia oportunidades para agricultura familiar 2015 [internet]. [acesso em 20 fev 2015]. Disponível em: http://www.mds.gov.br/saladeimprensa/noticias/2015/j aneiro/compra-institucional-amplia-oportunidades-paraagricultura-familiar

[10] Sabourin E. Acesso aos mercados para a agricultura familiar: uma leitura pela reciprocidade e a economia solidária. Rev Econ NE. 2014;45 Spec No:21-35.

[11] Sabourin E, Samper M, Le Coq JF, Massardier G, Sotomayor O. El surgimiento de políticas públicas para la agricultura familiar en América Latina: trayectorias, tendencias y perspectivas. Cad Ciên Tecnol. 2014;31(2):189-226.

[12] Guanziroli CE. Agricultura familiar e reforma agrária no século XXI. Rio de Janeiro: Editora Garamond; 2001.

[13] Belik W, Domene SMA. Experiências de programas combinados de alimentação escolar e desenvolvimento local em São Paulo - Brasil. Agroalimentaria. 2012;18(34):57-72.

[14] Fornazier A, Belik W. Produção e consumo local de alimentos: novas abordagens e perspectivas para políticas púbicas. Segurança Alimentar e Nutricional. 2013;20(2):204-218.

[15] Soares P. Análise do programa de aquisição de alimentos na alimentação escolar em um município de Santa Catarina [dissertação]. Florianópolis: Universidade Federal de Santa Catarina; 2011.

[16] Cavalli SB, Melgarejo L, Sousa AA, Lopes SJ, Soares P, Martinelli SS, et al. Estratégias de Gestão da Qualidade dos Vegetais e Frutas Fornecidos pelo Programa de Aquisição de Alimentos (PAA) para a Alimentação Escolar. Florianópolis: Universidade Federal de Santa Catarina, MCT, CNPq, MDS; 2012 (Contract no 563662/2010-7).

[17] Izumi BT, Alaimo K, Hamm MW. Farm-to-School Programs: Perspectives of School Food Service Professionals. JNEB. 2010;42(2):83-91.

[18] Chaim N, Belik W. São Bernardo do Campo: Atuação Pioneira em favor da Agricultura Familiar. In: Corá MAJ, Belik W (editores). Projeto Nutre SP: análise da inclusão da agricultura familiar na alimentação escolar no estado de São Paulo. São Paulo: Instituto Via Pública; 2012. p. 144.

[19] Taylor JC, Johnson RK. Farm to School as a strategy to increase children's fruit and vegetable consumption in the United States: Research and recommendations. Nutrition Bulletin. 2013;38(1):70-79.

[20] Zimmermann SA, Ferreira AP. El programa de adquisición de alimentos de la agricultura familiar em Mirandiba - PE. In: Scotto G (editor). Aun hay tiempo para el sol: pobrezas rurales y programas sociales Pobrezas rurales y programas sociales Brasil - Venezuela Guatemala - Una mirada desde lo local. Rio de Janeiro: Actionaid; 2008. p. 28-64.

[21] Vieira DFA, Del-Grossi ME. Influência do programa de aquisição de alimentos na comercialização dos produtos da agricultura familiar: o caso do município de Paracatu em Minas Gerais. Sociedade e Desenvolvimento Rural. 2010;4(2):28.

[22] Becker C, Sacco dos Anjos F. Segurança alimentar e desenvolvimento rural: limites e possibilidades do Programa de Aquisição de Alimentos da agricultura familiar, em municípios do sul gaúcho. Segurança Alimentar e Nutricional. 2010;17(12):61-72.

[23] FAO, IFAD, WFP. The State of Food Insecurity in the World 2014. Strengthening the enabling environment for food security and nutrition. Rome: Food and Agriculture Organization of the United Nations; 2014.

[24] Brasil. Dados cadastrais das Instituições de Ensino Superior no Brasil: Portal Brasileiro de Dados Abertos [internet]; 2011 [acesso em 05 mar 2015]. Disponível em: http://dados.gov.br/dataset/instituicoesde-ensino-superior/resource/20bf16da-6a37-4e3a-9e6acfe335641d4d.

[25] Soares P, Martinelli SS, Melgarejo L, Cavalli SB. Fornecimento de alimentos da agricultura familiar para a alimentação escolar: o exemplo do Programa de Aquisição de Alimentos. Segurança Alimentar e Nutricional. 2013;20(1):41-51.

[26] Marques AA, Fernandes MGM, Leite IN, Viana RT, Gonçalves MCR, de Carvalho AT. Reflections by family farmers on the dynamics of providing their products for school food: the case of Araripe, Ceará, Brazil. Saúde Soc. 2014;23(4):1316-1328.

[27] Proença RPC. Qualidade nutricional e sensorial na produção de refeições. Florianópolis: UFSC; 2005.

[28] Soares P, Martinelli SS, Melgarejo L, Davó-Blanes MC, Cavalli SB. Potencialidades e dificuldades para o abastecimento da alimentação escolar mediante a aquisição de alimentos da agricultura familiar em um município brasileiro. Ciênc. Saúde Coletiva. 2015;20(6):1891-1900. 
[29] Borjes LC, Cavalli SB, da Costa Proença RP. Proposal of vegetable classification considering nutritional and sensory characteristics and preparation techniques. Rev Nutr. 2010;23(4):645-654.

[30] Martinelli SS, Soares S, Fabri RK, Veiros MB, Cavalli SB. Qualidade da alimentação escolar: método para avaliação da Aquisição de Gêneros Alimentícios (AGA). Alimentação Escolar. 2015. No prelo.

[31] Delgado GC, Conceição JCP, Oliveira JJ. Avaliação do programa de aquisição de alimentos da agricultura familiar (PAA). Brasília: Ministério do Planejamento, Orçamento e Gestão, IPEA - Instituto de Pesquisa Econômica Aplicada; 2005.

[32] Müller A, Fialho M, Schneider S. A inovação institucional e a atuação dos atores locais na implementação do Programa de Aquisição de Alimentos no Rio Grande do Sul. Sociedade e Desenvolvimento Rural. 2007;1(1):1-21.

[33] Turpin ME. A alimentação escolar como fator de desenvolvimento local por meio do apoio aos agricultores familiares. Segurança Alimentar e Nutricional. 2009;16(Supl 2):20-42.

[34] Gomes CAO, Alvarenga ALB, Junior MF, Cenci SA, de Alimentos EA. Hortaliças minimamente processadas: Embrapa Informação Tecnológica. Rio de Janeiro: Embrapa Agroindústria de Alimentos; 2005.

[35] Proença RPC. Inovações Tecnológicas na Produção de Alimentação Coletiva. Florianópolis: Insular; 2000.

[36] Prezotto LL. Uma concepção de agroindústria rural de pequeno porte. Revista de Ciências Humanas. 2002 (31):133-153.

[37] Hanashiro MM, Belik W, Leite BC, Bambini MD, Vian CEdF, editors. Relações de coordenação na cadeia produtiva dos produtos minimamente processados. 46th Congress; 2008 July 20-23; Rio Branco, Acre, Brasil: Sociedade Brasileira de Economia, Administracao e Sociologia Rural (SOBER).

[38] Pereira EL, Rodrigues A, Ramalhosa E. Influence of working conditions and practices on fresh-cut lettuce salads quality. Food Control. 2013;33(2):406-412.

[39] Triches RM, Schneider S. Alimentação escolar e agricultura familiar: reconectando o consumo à produção. Saúde Soc. 2010;19(4):933-945.

[40] Oliveira D, Gazolla M, Schneider S. Produzindo novidades na agricultura familiar: agregação de valor e agroecologia para o desenvolvimento rural. Cad Ciên Tecnol. 2011;28(1):17-49.

[41] Federação das Indústrias do Estado de São Paulo FIESP, Instituto de Tecnologia de Alimentos - ITAL. Brasil Food Trends. São Paulo; 2010.

[42] Vieira PF, Cazella AA, Cerdan C, Carrière J-P. Desenvolvimento territorial sustentável no Brasil: subsídios para uma política de fomento. Florianópolis: APED; 2010.

[43] Wilkinson J. A pequena produção e sua relação com os sistemas de distribuição. Porto Alegre: EdUFRGS; 2008.

[44] Baldwin C, Wilberforce N, Kapur A. Restaurant and food service life cycle assessment and development of a sustainability standard. Int J Life Cycle Assess. 2011;01;16(1):40-49.

[45] Wang YF, Chen SP, Lee YC, Tsai CT. Developing green management standards for restaurants: An application of green supply chain management. Int J Hospitality Management. 2013;34(1):263-273.

[46] Sharma A, Moon J, Strohbehn C. Restaurant's decision to purchase local foods: Influence of value chain activities. Int J Hospitality Management. 2014;39:130-143.

[47] Sustainable Food Policy. A Guide to Developing a Sustainable Food Purchasing Policy; 2007.

[48] Brasil. Decreto no 7.794, de 20 de agosto de 2012. Institui a Política Nacional de Agroecologia e Produção Orgânica. Diário Oficial da União. 21 ago 2012.

[49] Brasil. Lei no 11.346, de 15 de setembro de 2006. Cria o Sistema Nacional de Segurança Alimentar e Nutricional - SISAN - com vistas em assegurar o direito humano à alimentação adequada e dá outras providências. Diário Oficial da União; 18 set 2006.

[50] Biological Farmers of Australia Group. Annual Report. Biological Farmers of Australia Limited; 2011.

[51] Schneider MK, Lüscher G, Jeanneret P, Arndorfer M, Ammari Y, Bailey D, et al. Gains to species diversity in organically farmed fields are not propagated at the farm level. Nature Communications. 2014;5.

[52] Baranski M, Srednicka-Tober D, Volakakis N, Seal C, Sanderson R, Stewart GB, et al. Higher antioxidant and lower cadmium concentrations and lower incidence of pesticide residues in organically grown crops: a systematic 
literature review and meta-analyses. $\mathrm{Br} \mathrm{J}$ Nutr. 2014;112(5):794-811.

[53] Ponisio LC, M'Gonigle LK, Mace KC, Palomino J, Valpine PD, Kremen C. Diversification practices reduce organic to conventional yield gap. Proceedings of the Royal Society B: Biological Sciences. 2015;282(1799).

[54] Lima EE, Sousa AA. Alimentos orgânicos na produção de refeições escolares: limites e possibilidades em uma escola pública em Florianópolis. Rev Nutr. 2011;24(2):263-273.

[55] Silva APF, Sousa AA. Alimentos orgânicos da agricultura familiar no Programa Nacional de alimentação Escolar do Estado de Santa Catarina, Brasil. Rev Nutr. 2013;26(6):701714.

[56] Harmon AH, Gerald BL. Position of the American Dietetic Association: food and nutrition professionals can implement practices to conserve natural resources and support ecological sustainability. J Am Diet Assoc. 2007;107(6):1033-1043.

[57] Veiros M, Proença RPdC. Princípios da sustentabilidade na produção de refeições. Revista Nutrição em Pauta. 2010:45-49.
[58] Gabriel CG, Calvo MCM, Vasconcelos FAG, Lacerda JT, Freitas SFT, Schmitz BAS. Evaluation of municipal management of the Brazilian National School Nutrition Program in the largest cities of Santa Catarina State, Brazil. Cad Saúde Pública. 2014;30(9):2017-2023.

[59] Oosterveer P, Guivant J, Spaargaren G. Alimentos verdes em supermercados globalizados: uma agenda teórico-metodológica. In: Guivant J, Spaargaren G, Rial C. (organizadores). Novas práticas alimentares no mercado global. Florianópolis: UFSC; 2010. p. 15-57.

[60] Villar BS, Schwartzman F, Januario BL, Ramos JF. Situação dos municípios do estado de São Paulo com relação à compra direta de produtos da agricultura familiar para o Programa Nacional de Alimentação Escolar (PNAE). Rev Bras Epidemiol. 2013;16(1):223-226.

[61] Saraiva EB, Silva APF, Sousa AA, Cerqueira GF, Chagas CMS, Toral N. Panorama da compra de alimentos da agricultura familiar para o Programa Nacional de Alimentação Escolar. Ciênc Saúde Coletiva. 2013;18(4):927-935. 